\title{
ВОЗНИКНОВЕНИЕ ФОНДОВЫХ ПУЗЫРЕЙ И ИХ РАННЯЯ ИДЕНТИФИКАЦИЯ
}

\author{
(c) 2019 Коновалова Мария Евгеньевна \\ доктор экономических наук, заведующий кафедрой экономической теории \\ Самарский государственный экономический университет, Россия, Самара \\ E-mail:mkonoval@mail.ru \\ (c) 2019 Кузьмина Ольга Юрьевна \\ кандидат экономических наук, доцент кафедры экономической теории \\ Самарский государственный экономический университет, Россия, Самара \\ E-mail: pisakina83@yandex.ru
}

\begin{abstract}
В статье рассмотрены проблемы экономической безопасности страны с точки зрения идентификации финансовых кризисов. Раскрыты сущность и содержание финансового кризиса, вывялены характерные черты фондового пузыря, как неотъемлемой составляющей фондового кризиса. Особое внимание уделено изучению существующих методик идентификации и измерения пузырей. Авторами осуществлен анализ современных фондовых кризисов, выделены факторы уязвимости российского финансового рынка. В статье проведена оценка возможности возникновения фондового кризиса в России на современном этапе, результатом которой стало построение многофакторной модели по идентификации фондового пузыря. Обоснованы предложения и рекомендации по устранению существующих проблем российского фондового рынка с целью нивелирования угроз экономической безопасности страны.
\end{abstract}

Ключевые слова: финансовый кризис, фондовый рынок, фондовый пузырь, индикаторы финансового кризиса, экономическая безопасность

Фондовый рынок по своему предназначению выполняет одну из важнейших функций, заключающуюся в привлечении инвестиций в реальный сектор экономики [1]. Но когда механизмы функционирования рынка нарушаются, и он перестает адекватно оценивать стоимость финансовых инструментов, велика вероятность возникновения такого явления, как фондовый кризис. Фондовые кризисы довольно частое явление, они носят системный характер и могут распространяться по всему миру при потрясении на одном из рынков.

Статья посвящена исследованию проблемы идентификации финансовых кризисов с целью минимизации их отрицательного воздействия на экономическую безопасность страны. Во многих случаях финансовые кризисы начинаются именно с фондового сектора, в связи с чем анализ закономерностей фондовых кризисов представляется наиболее интересным. Чтобы преодолеть кризис, нужно быть к нему готовым заранее, своевременная идентификация фондового кризиса позволит не только принять правильные решения инвесторам, но и помочь государственным органам смягчить его негативные последствия или вовсе предотвратить.

Для реализации поставленной в ходе исследования проблемы необходимо решить следующие задачи. Во-первых, определить характерные черты фондового пузыря и рассмотреть существующие методы его идентификации и измерения на рынке ценных бумаг. Во-вторых, осуществить ретроспективный анализ причин и факторов, влияющих на возникновение кризисов на российском фондовом рынке. В-третьих, определить факторы кризисной уязвимости российского рынка ценных бумаг и предложить инструменты повышения финансовой устойчивости.

Основной целью работы является развитие теоретико-методологических положений процесса формирования и развития финансовых кризисов. В зарубежной и отечественной научной литературе еще не сформировалось единого и общепринятого подхода к прогнозированию кризисов и пузырей на рынке ценных бумаг, что формирует запрос общества на фундаментальное и поисковое исследование проблем, связан- 
ных с ранней идентификацией финансовых пузырей. Необходимо также обосновать основные направления по совершенствованию финансовых отношений, обусловливающие повышение эффективности функционирования фондового рынка.

Среди зарубежных исследователей первый, кто посвятил свои труды непосредственно проблематике фондовых кризисов и пузырей, является Ч. Киндлебергер. Именно его работы стали толчком для целой серии исследований. Дальнейшее развитие вопроса фондовых кризисов нашло свое отражение в работах Б. Айхенгрина, Д. Сорнетте, О. Бланшара, М. Бордо, А. Вайла, Р. Дорнбуш， Ф. Дэвиса, Г. Кальво, Ф. Мишкина, М. Обстфельда, С. Раделет, К. Рейнхарта, К. Рогоффа, Д. Сакса, Ю. Уайта, П. Кругмана, Д. Стиглица, Р. Шиллера и др.

Значительный вклад в разработку теоретических и методологических вопросов изучения финансовых кризисов внесли такие отечественные ученые, как А.В. Аникин, 3. В. Атлас, М.В. Ершов, А.В. Бузгалин, Л.Н. Красавина, Я.М. Миркин, Б.Б. Рубцов и К.В. Рудый. Также сохраняют свою актуальность труды ученых советского периода, а именно работы Э.Я. Брегеля, Е.С. Варги, Н.Д. Кондратьева, академика И.А. Трахтенберга. Анализом причин возникновения пузырей занимались С.Ю. Глазьев, Е.В. Чиркова и Н.А. Станик, М.Л. Дорофеев. Стоит отметить, что проблема моделирования фондовых пузырей является мало изученной в российской экономической литературе.

Методологической основой исследования выступают следующие общенаучные методы познания явлений и процессов: методы логического, диалектического и исторического анализа, системный подход к анализу кризисных явлений на финансовых рынках и разработке методов их ранней идентификации. Также широко использовались методы статистического, эконометрического анализа, экономико-математического моделирования. Данные методы в совокупности с теоретическими положениями и экономической информацией позволили обеспечить достоверность и обоснованность полученных в работе результатов и выводов.

Рассмотрев различные теоретические представления о природе финансовых кризисов, а также их количественных характеристик, мы пришли к выводу, что единого подхода к по- ниманию проблемы так и не сформировалось. Безусловно, количественные характеристики пузырей весьма субъективны и значительно варьируются в зависимости от характера рынка, его национальной принадлежности, масштабов и множества других факторов. Применительно к России, исследований в этой области проводилось не так много, чтобы с уверенностью можно было применять те или иные параметры пузырей, а использование зарубежных методик представляется не совсем корректным в виду существенных различий между рынками. Своевременная идентификация фондового кризиса позволит не только принять правильные решения инвесторам, но и помочь государственным органам смягчить негативные последствия кризиса или вовсе его предотвратить [2]. Разработка необходимой методологии для диагностирования кризисов позволит разрешить данную проблему.

Исходя из истории биржевых кризисов, становится очевидным, что чаще всего их причиной является фондовый пузырь.

Термин «пузырь» применяется для обозначения устойчивого превышения цены актива над его фундаментальной стоимостью. То есть при его выявлении необходимо знать фундаментальную стоимость актива, расчет которой не является простым и очевидным; срок и величину превышения цены актива над его фундаментальной стоимостью. Многочисленные попытки многих исследователей и аналитиков уточнить данные критерии не принесли реальных результатов, все полученные результаты достаточно субъективны и не могут быть раз и навсегда зафиксированы. В связи с этим на сегодняшний день так и не сложилось общепринятого количественного определения фондового пузыря [3].

1. Наиболее распространенным методом является использование макроэкономических индикаторов и коэффициентов [4]. В качестве таковых могут выступать величина денежного предложения в экономике, уровень доходов населения, склонность к сбережению, дефицит бюджета, торговый и платежный балансы страны и многие другие. Однако применительно к рынку ценных бумаг каждый из них может лишь приблизительно охарактеризовать ситуацию, и уж точно не распознать пузырь. В этом случае применяются более специализированные ма- 
кроэкономические показатели, например:

- мультипликатор P/E (цена/прибыль), учитывающий суммарную капитализацию всех существующих эмитентов к выработанной ими прибыли, и другие производные показатели;

- коэффициенты дивидендной доходности: D/P (дивиденд на акцию /цена) или TDiv/ MCap (дивиденды выплачиваемые по всему рынку акций/капитализация рынка акций);

- $\quad$ капиталоемкость ВBП - MCap/GDP, отражающая отношение совокупной капитализации рынка к номинальному ВВП страны;

- коэффициент Q Тобина, рассчитываемый как отношение рыночной цены стоимости активов к цене их замещения.

Особенности российского рынка не позволяют адекватно рассчитать некоторые из этих показателей. Например, в периоды кризиса прибыли множества компаний имеют отрицательные значения, что делает невозможным использование ценовых мультипликаторов, а нестабильная дивидендная политика будет весьма искажать коэффициенты дивидендной доходности. Что касается коэффициента Тобина, то он дает адекватные результаты применительно к одной конкретной фирме, а расчет для всего фондового рынка представляется сложным и требует сбора данных по каждой из компаний, акции которых функционируют на фондовом рынке. Наиболее прост в расчетах и понятен только MCap/GDP.

2. Эконометрические методы предполагают оценку отклонения текущей рыночной цены от ее справедливого значения. Признаком наличия пузыря будет являться наличие системных отклонений вверх или вниз в остатках от траектории, смоделированной на основе гипотетических представлений, базирующихся на учете фундаментальных факторов, от фактической траектории изменения показателя. Если же отклонения от смоделированных значений ведут себя как «белый шум», то эту ситуацию не рассматривают как пузырь. При таком подходе речь идет о привязке к набору фундаментальных факторов, который не всегда может оказаться исчерпывающим. Однако проверка адекватности результатов затруднена, поскольку не существует общепризнанного мнения, какие всплески цены считать пузырем, за исключением нескольких самых крупных пузырей, существование которых не вызывает сомнений.

Идентифицировать пузырь можно также с помощью эмпирических тестов Н. Балке и М. Вохара, Р. Флуда и Р. Хондрика, Б.Т. Диба и Х.И. Гроссмана [5] и др.

3. Статистические методы включают в себя анализ временных рядов посредством корреляционного и регрессионного анализа, методики выделения компонент временного ряда, модели прогнозирования с распределенными лагами, VAR (стоимость подверженная риску) и др. Российскими учеными по аналогии с VAR был разработан новый метод, позволяющий измерять и мониторить риск возникновения пузыря,- MAR (метод оценки массы риска).

Эконометрические и статистические методы считаются классическими. Они основаны на том, что наблюдаемые экономические данные, составляющие временной ряд, подчинены нормальному распределению и являются независимыми. Однако большинство экономических процессов, в том числе и динамика фондового рынка, развиваются хаотично, нелинейно, поэтому описывать их с помощью традиционных статистических методов некорректно. В связи с этим, в последнее время развиваются альтернативные методы анализа - нелинейная динамика, основанная на теории нейронных сетей, теории хаоса, синергетике, теории фракталов, катастроф и нечетной логики и т.д.

4. Еще одними методами по идентификации фондовых пузырей являются эконофизические методы. Эконофизика как самостоятельная наука занимается применением методологии теоретической физики к анализу экономических данных и переносом аналогий из физики на финансовые явления. В области фоновых кризисов ученые-физики построили модель, согласно которой все участники рынка были разделены на рациональных и иррациональных агентов (шумовых агентов). Данные категории участников сбалансированы между собой до тех пор, пока цена актива находится на одном уровне. Как только она начинает расти, возрастает количество рациональных инвесторов: они стремятся выйти с рынка и реализовать свой актив. С каждым вышедшим рациональным инвестором приходит все большее количество иррациональных агентов, что приводит к агрессивному росту цен, формированию пузырей и последующим их схлопываниям. Таким образом была апробирована и перенесена на фондовый рынок физическая теория самоорганизованной критичности - 
свойство систем периодически воспроизводить критическое состояние.

5. Диагностировать пузырь можно и с помощью инструментов технического анализа, предполагающих использование визуально-графических фигур, которые образует график цены на тот или иной актив. При этом аналитики, использующие технический анализ, полагают, что искать внутреннюю стоимость актива нет необходимости, поскольку рыночные цены уже заключают в себе всю возможную информацию, достаточную для идентификации пузыря.

6. Альтернативным направлением исследования пузырей на фондовом рынке являются лабораторные исследования в рамках экспериментальной экономики. В отличие от реальной действительности, сложившейся на финансовом рынке, где практически невозможно точно определить справедливую стоимость того или иного актива (так как она имеет вероятностный характер и определяется ожиданиями участников относительно будущего), в экспериментальных исследованиях она может быть известна всем участникам эксперимента.

Описанные методы диагностируют пузыри, оценивая фундаментальное значение финансового актива и величину отклонения наблюдаемой цены от фундаментального значения. Однако фундаментальное значение не является наблюдаемой величиной, поэтому даже при ретроспективном анализе оценка фундаментального значения затруднена.

Использование только одного подхода, по нашему мнению, является недостаточным при выявлении финансовых пузырей, поскольку существует риск неустранимых упущений, присущих тому или иному методу в отдельности. Поэтому корректнее использовать комплексный анализ выявления пузырей, который позволит охарактеризовать разные стороны фондового рынка: поведенческий фактор, макроэкономическую среду, системные ошибки и влияние различных факторов [6].

Анализ процесса идентификации финансового пузыря осуществлялся в три этапа: тестирование российского фондового рынка на его эффективность, тестирование цен финансовых активов, включающее в себя макроэкономический, факторный и фрактальный анализ цен финансовых инструментов, обращающихся на российском фондовом рынке. В завершении исследования интерпретировались полученные результаты, с точки зрения оценки возможности возникновения фондового пузыря.

Для выявления автокорреляционной зависимости с целью определения степени эффективности фондового рынка России был произведен расчет значений статистики Дарбина-Уотсона с 10-ю временными лагами на основании ежедневной динамики индекса MOEX.

Полученные результаты показали, что наблюдается автокорреляционная зависимость между уровнями ряда, начиная с 7-го лага (за исключением отдельных периодов, когда зависимость была выявлена на меньших лагах). Следовательно, можно сделать вывод, что при принятии инвестиционных решений участники полагались на информацию о предыдущей динамике индекса, то есть поведение игроков характеризуется подражательными и имитационными элементами.

K 2012 г. при восстановлении экономики после кризиса 2008 г. наблюдается стабилизация динамики рынка, без каких-либо явных признаков наличия пузыря, но уже к 2014 г. автокорреляционная зависимость возвращается и вновь характеризует рынок ажиотажным поведением биржевых игроков. В 2018 г. и I квартале 2019 г. рынку также свойственны всплески положительной автокорреляции, особенно в последние месяцы.

Таким образом, проведенный анализ показал, что российскому фондовом рынку присуща слабая степень эффективности. Поскольку информационная неэффективность является основной предпосылкой формирования финансовых пузырей, о наличии последних на нашем рынке можно утверждать с высокой степенью вероятности.

Тест цены финансово актива на предмет наличия пузыря предполагает в начале проведение анализа макроэкономических дисбалансов с помощью показателя MCap/GDP (рис. 1).

Пороговое значение было рассчитано как сумма математического ожидания и среднеквадратического отклонения за исследуемый период, и составило 62,3\%. Сравнение данного значения с расчётными позволит выявить диспропорции в динамике фондового рынка и экономики в целом. 


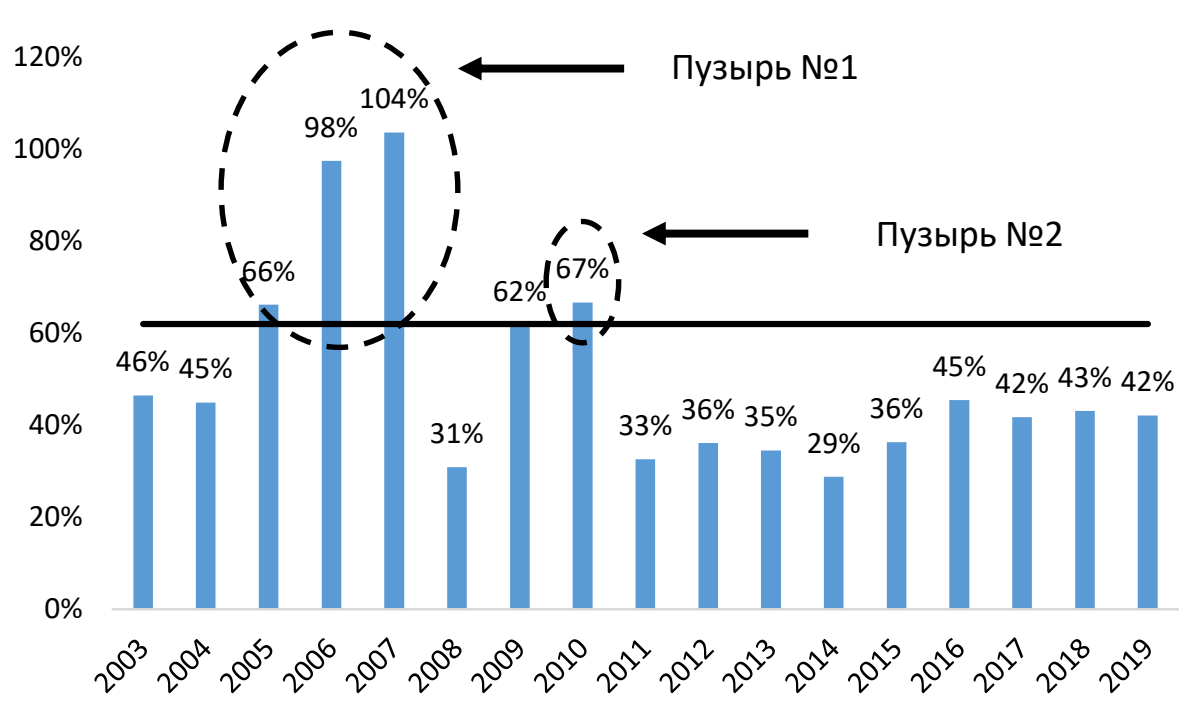

Рuc. 1. Динамика показателя MCap/GDP

Источник: составлено авторами на основе проведенных расчетов

\section{Библиографический список}

1. Михайлов А.М., Искандаров Т.С., Городнов В.А. Роль фондового рынка в финансировании экономики РФ // Экономические науки. 2019. № 173. С. 22-26.

2. Tarullo, D.K. Financial regulation: Still unsettled a decade after the crisis// Journal of Economic Perspectives.2019. - № 33(1). - P. 61-80.

3. Makin, A.J. Lessons for macroeconomic policy from the Global Financial Crisis// Economic Analysis and Policy. 2019. - № 64.- P. 13-25.

4. Zhang G., W. Liu, W. Analysis of the international propagation of contagion between oil and stock markets// Energy. - 2018. - № 165.- P. 469-486.

5. Дорофеев, М.Л. Моделирование процессов финансовых пузырей на российском фондовом рынке// Финансы и кредит. - 2016. -№ 15.- С. 49-63.

6. Станик Н.А. Кризисы на рынке ценных бумаг: характерные черты и методы ранней идентификации: дис. канд. экон. наук: 08.00.10: защищена 21.10.13: утв. 24.10.13 / Станик Наталья Андреевна. - М., 2013. - 102 с. 